\title{
Effect of Surface Polishing Treatment on the Fatigue Performance of Shot-Peened Ti-6Al-4V Alloy
}

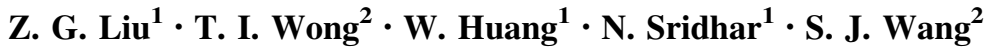

Received: 5 October 2016/Revised: 24 November 2016/Published online: 10 March 2017

(C) The Chinese Society for Metals and Springer-Verlag Berlin Heidelberg 2017

\begin{abstract}
In this study, shot peening is applied to the titanium alloy Ti-6Al-4V, and the surface treatment effect on fatigue life of shot-peened specimens under high cycle loading is investigated. The induced residual stress is measured by using the orbital hole-drilling method. Surface profilometer and optical microscopy are employed to characterize the surface roughness and morphology. The deformed microstructure layers of the shot-peened specimens are investigated by using scanning electron microscopy. Experiments reveal that the fatigue life of $\mathrm{Ti}-6 \mathrm{Al}-4 \mathrm{~V}$ is improved by the shot peening process, and the surface pre-peening polishing. The combination of pre- and post-peening polishing treatments further improves fatigue life of Ti-6Al-4V specimens. The present work provides useful guidelines for developing more efficient shot peening strategies.
\end{abstract}

KEY WORDS: Shot peening; Surface polishing treatment; Fatigue; Residual stress; Ti-6Al-4V alloy

\section{Introduction}

Shot peening is a cold-working process in which the surface of substrate is impacted with small metallic shots. In the process, the impact deforms the surface of substrate permanently, which produces local plastic deformation and manifests a compressive residual stress (CRS) zone beneath the surface [1-4]. Generally, shot peening results in surface layer changes in different aspects, such as residual stress, surface roughness and surface hardening. The fatigue life enhancement is mainly attributed to the CRS zone which can deter the occurrence of fatigue crack

Available online at http://link.springer.com/journal/40195.

S. J. Wang

sj-wang@imre.a-star.edu.sg

1 Institute of High Performance Computing, A*STAR, 1 Fusionopolis Way, Singapore 138632, Singapore

2 Institute of Materials Research and Engineering, A*STAR, 2 Fusionopolis Way, Singapore 138634, Singapore initiation. Crack nucleation is often observed to occur beneath the CRS zone, and the slight surface roughness caused by shot peening will not result in a dramatic decrease in the fatigue life [5-8].

A large number of studies have demonstrated that fatigue performance is improved by shot peening process. These studies were carried out for different shot sources or material systems, but the same mechanism of shot peeninginduced CRS which retards crack propagation and enhances fatigue life is valid. For instance, Luong and Hill [9] reported that shot peening process generates a large CRS beneath the surface of 7075-T7451 Al alloy and has a residual stress of up to about $75 \%$ of yield strength of the material, and typically about $0.25 \mathrm{~mm}$ in depth. These characteristics increase fatigue life dramatically. Zammit et al. [10] investigated the factors which improving fatigue life of shot-peened austempered ductile iron (ADI) and found out that the shot peening specimens exhibited about $61 \%$ increase in fatigue life over that of as-received specimens. This result was explained by the shifting of crack initiation to the sub-surface beneath the CRS zone in the shot peening-affected areas. The surface hardness also 
increased from 370 to $535 \mathrm{HV}$. Similar results were also obtained in the work of Cho et al. [11], and they found that the surface hardness of Al-2024 alloy increases up to about $140 \mathrm{HV}$ by shot peening treatment from $65 \mathrm{HV}$ of the base material. Recently, Fargas et al. [12] studied fatigue life of AISI-301LN steel after shot peening of annealed and coldrolled specimens. Their results showed that the shot-peened cold-rolled specimens showed significant improvement in fatigue limit due to the absence of micro-cracks on the substrate. Kikuchi et al. [13] reported the fatigue properties of shot-peened Al-5056 alloy using ultra-fine peen particles (diameter $\sim 10 \mu \mathrm{m}$ ), and they found that the fatigue life of the ultra-fine peen-treated specimens increased dramatically by shot peening, because the generated surface roughness was low, and then, the release of the CRS during fatigue tests is small especially under low stress amplitude. In general, the craters caused by shot peening can be a source of fatigue crack initiation, and consequently, the fatigue strength could be decreased when surface roughness is severe, which is commonly referred to as overpeening [14-17]. In reality, shot peening-induced CRS is also often exposed to thermal or mechanical loads, and thus, the residual stress in the shot peening-affected area may be redistributed and relaxed, which could weaken the achievable advantages from shot peening and increase the complexity and uncertainty in fatigue life prediction $[18,19]$. Therefore, in order to better estimate the role of different shot peening factors on the fatigue life, the microstructure needs to be examined and the contribution of CRS to the enhancement of fatigue strength needs to be quantified.

Ti-6Al-4V alloy is commonly used in industrial application, due to its high strength-to-weight ratio. There are extensive studies on fatigue life enhancement by shot peening for this material. For example, Xie et al. [20] investigated the CRS and microstructure of Ti-6Al-4V matrix-reinforced composites after shot peening. Their results revealed that both CRS and micro-hardness increased with the increase in shot peening intensity. Jiang et al. [21] investigated the effects of shot-peening and reshot-peening on fatigue behavior of Ti-6Al-4V alloy, and both processes enhanced fatigue life greatly. Zhang et al. [22] studied the effects of multiple laser peening and peening intensity on fatigue performance of $\mathrm{Ti}-6 \mathrm{Al}-4 \mathrm{~V}$ alloy by using consecutive laser shocks. It is found that the fatigue life of the laser-peened specimen does not monotonically increase as multiple overlapping laser spots are applied. Similar laser shock peening studies were also reported in the work of Luong and Hill [9] and Gao [23] for 7075-T7451 Al alloy. Other studies for $\mathrm{Ti}-6 \mathrm{Al}-4 \mathrm{~V}$ are concentrating on the effect of shot peening on fretting fatigue of specimen, such as Martinez et al. [24] and Lee and Mall [25]. These investigations provide much insight into fatigue life enhancement by shot peening process.

However, few studies about the effect of polishing treatment on fatigue enhancement of shot-peened Ti-6Al$4 \mathrm{~V}$ alloy have been reported, especially the relation of polishing parameters and fatigue strength has not been quantitatively clarified. We note that even though the depth of the CRS zone can be increased by increasing the shot peen intensity, increased intensity will also increase surface roughness [26], which can reduce fatigue life. Montross et al. [27] indicated that the post-peening polishing treatment can promote surface quality, but this treatment will offset the benefits of shot peening since the CRS layer thickness is potentially reduced. Therefore, we study the effect of surface polishing treatment on the fatigue life of shot-peened $\mathrm{Ti}-6 \mathrm{Al}-4 \mathrm{~V}$ alloy systematically in this work. First, shot peening experiments and the variations of residual stress under different shot peening conditions are presented. Second, the fatigue life of shot-peened specimens is obtained experimentally under different conditions. Surface roughness is measured by surface profilometer. Surface morphology as well as the microstructure within the shot peening-affected area is examined. The effects of surface polishing treatment before and after shot peening processes on the fatigue life are studied in detail.

\section{Experiments}

Titanium alloy $\mathrm{Ti}-6 \mathrm{Al}-4 \mathrm{~V}$ is employed in this study. The nominal chemical composition of the alloy is shown in Table 1. Its mechanical properties are yield stress $\sigma_{y}$ of $880 \mathrm{MPa}$, tensile strength $\sigma_{u}$ of $950 \mathrm{MPa}$ and elongation at break of $14 \%$. Shot peening experiments are conducted under different conditions. The dimensions of the specimen used for fatigue tests are $78 \mathrm{~mm} \times 20 \mathrm{~mm} \times 2.3 \mathrm{~mm}$.

\subsection{Shot Peening and Fatigue Experiments}

Shot peening experiments are carried out in a well-designed setup through a duckbill nozzle. Figure 1 shows the details of the experimental flow diagram. In the controlled shot peening process, the main process parameters are pressure, shot flow rate and impact angle. For the process, the surface must sustain a certain coverage density. Interference may happen on the surface when many shots are

Table 1 Chemistry components of Ti-6Al-4V alloy

\begin{tabular}{llllllllll}
\hline $\mathrm{Al}$ & $\mathrm{V}$ & $\mathrm{C}$ & $\mathrm{N}$ & $\mathrm{O}$ & $\mathrm{H}$ & $\mathrm{Fe}$ & $\mathrm{Y}$ & $\mathrm{Ti}$ & Others \\
\hline 6.12 & 4.0 & 0.08 & 0.5 & 0.2 & 0.0125 & 0.3 & 0.005 & 0.1 & Balance \\
\hline
\end{tabular}




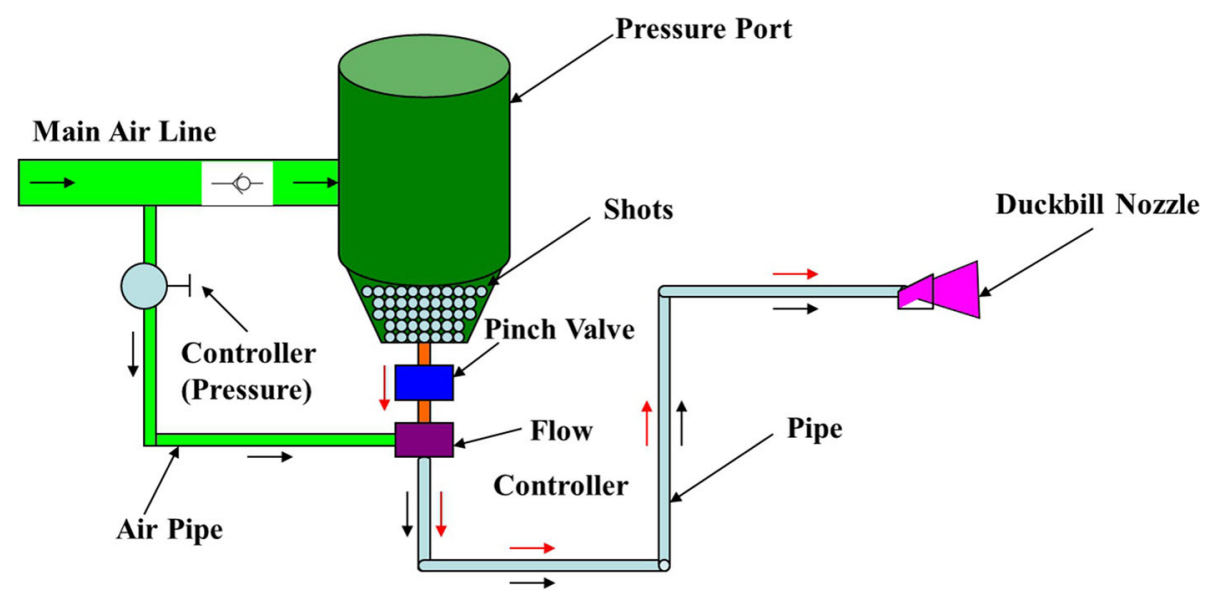

Fig. 1 Schematic diagram of shot peening test setup

projected at the same time. Besides, the rebound shot can cause surface damage due to improper angle of impact [28]. Generally, there are three types of air-controlled shot peening machines, i.e., gravity, pressure and suction, among which the pressure-controlled shot peening machine achieves the highest peening efficiency. In this study, pressure-controlled peening system was used, and the angle of impact of the shot peening nozzle toward the target is kept close to normal ( $89^{\circ}$ impact). The nozzle speed is kept constant at $60 \mathrm{inch} / \mathrm{min}$, which keeps the shot peening coverage at $100 \%$. The shot type is S110 cast steel (diameter is $0.28 \mathrm{~mm}$ ).

Full-scale tests of Ti-6Al-4V specimen are carried out in a fatigue component system (Instron 8872-J2070). The system consists of a hydraulic power unit to provide a constant amplitude cyclic loading. The operating frequency is $5 \mathrm{~Hz}$. Tests are performed with a stress ratio $R=0.1$ at room temperature. The fatigue life under high cycle loading for Ti-6Al-4V specimens is determined and denoted as cycles-to-failure in the experiments. It is noted that the fatigue failure of the test specimen is defined as when cracks are visually observed or deemed as a run-out when 2 million cycles are reached without any sign of cracking.

In this study, the fatigue life of Ti-6Al-4V alloy specimens under various treatment conditions is documented through experiments. Table 2 illustrates the treatment processes under various conditions in each batch of experiments. In order to investigate the effect of surface polishing treatment on fatigue life of specimens comprehensively, three batches of tests were carried out, which correspond to the study cases of post-peening polishing, pre-peening polishing and combined pre- and post- peening polishing treatments. The detailed shot peening test configuration used in three batches of tests is listed in Table 3. It is noted that the tests are carried out in the same machine to minimize the measurement error in experiments.

\subsection{Residual Stress Measurement and Surface Characterization}

The residual stresses were measured by target strain gauge orbital hole-drilling method [29-31]. For each specimen, the target site is degreased and subjected to light abrasion to remove the largest asperities from the treated surface. This is carried out by using 400 grades $\mathrm{SiC}$ paper with very light hand pressure. A final degreasing process (acetone) is performed at each site. In the hole-drilling method, one target strain gauge is to be installed and drilled in the center of upper surface. Each gauge is positioned about $4 \mathrm{~mm}$ from the center of the upper surface with element 1 aligned in the longitudinal direction and element 3 in the transverse direction. One example after gauge installation is shown in Fig. 2a. Gauges are drilled using a PC-controlled 3-axis drilling machine; depth increments are set at $6 \times 16 \mu \mathrm{m}+5 \times 32 \mu \mathrm{m}+6 \times 64 \mu \mathrm{m}+6 \times 128 \mu \mathrm{m}$, giving a completed hole depth of $1.41 \mathrm{~mm}$ for the determination of stress to a depth of $1024 \mu \mathrm{m}$. A typical arrangement for incremental drilling is shown in Fig. 2b. Within the data reduction program, the strain data are subjected to a moving average smoothing process and then reduced to normal stress $\left(\sigma_{1}\right.$ and $\left.\sigma_{3}\right)$ and shear stress $\left(\tau_{3}\right)$ components at given depth increments. Residual stress is then resolved into maximum and minimum principal stresses at each depth.

The measurement of surface roughness is an important parameter to be measured for analysis of the shot peening process [32]. There are various techniques to measure the surface roughness depending on the resolution and the limitations of the equipment. In this study, the stylus method is used for surface roughness measurement. The data are collected using a surface profilometer (KLA Tencor, P16+). The measured results are expressed as Ra or average roughness, which is the arithmetic value of the deviation of the trace above and below the center line. The magnitude of $\mathrm{Ra}$ is measured in micrometers. The 
Table 2 Treatment processes under various conditions

\begin{tabular}{|c|c|c|c|}
\hline Tests & Test labels & Specimens & Processes \\
\hline \multirow[t]{7}{*}{ First batch } & $\mathrm{T} 1-1$ & Intrinsic & Specimen without any treatment \\
\hline & $\mathrm{T} 1-2$ & SP30 & Specimen with shot peening under pressure $30 \mathrm{psi}$ \\
\hline & $\mathrm{T} 1-3$ & SP50 & Specimen with shot peening under pressure $50 \mathrm{psi}$ \\
\hline & $\mathrm{T} 1-4$ & SP70 & Specimen with shot peening under pressure $70 \mathrm{psi}$ \\
\hline & $\mathrm{T} 1-5$ & SP30 V & Specimen with shot peening under pressure $30 \mathrm{psi}+$ surface polishing \\
\hline & T1-6 & SP50 V & Specimen with shot peening under pressure $50 \mathrm{psi}+$ surface polishing \\
\hline & $\mathrm{T} 1-7$ & SP70 V & Specimen with shot peening under pressure $70 \mathrm{psi}+$ surface polishing \\
\hline \multirow[t]{6}{*}{ Second batch } & $\mathrm{T} 2-1$ & Intrinsic & Specimen without any treatment \\
\hline & $\mathrm{T} 2-2$ & VS & Specimen with surface polishing only \\
\hline & $\mathrm{T} 2-3$ & VSP30 & Specimen with surface polishing + shot peening under pressure $30 \mathrm{psi}$ \\
\hline & $\mathrm{T} 2-4$ & VSP50 & Specimen with surface polishing + shot peening under pressure $50 \mathrm{psi}$ \\
\hline & $\mathrm{T} 2-5$ & VSP60 & Specimen with surface polishing + shot peening under pressure $60 \mathrm{psi}$ \\
\hline & $\mathrm{T} 2-6$ & VSP70 & Specimen with surface polishing + shot peening under pressure $70 \mathrm{psi}$ \\
\hline \multirow[t]{7}{*}{ Third batch } & T3-1 & Intrinsic & Specimen without any treatment \\
\hline & T3-2 & VS & Specimen with surface polishing only \\
\hline & T3-3 & VSP & Specimen with surface polishing + shot peening \\
\hline & T3-4 & VSP2H & Specimen with surface polishing + shot peening $+2 \mathrm{~h}$ surface polishing \\
\hline & T3-5 & VSP4H & Specimen with surface polishing + shot peening $+4 \mathrm{~h}$ surface polishing \\
\hline & T3-6 & VSP6H & Specimen with surface polishing + shot peening $+6 \mathrm{~h}$ surface polishing \\
\hline & $\mathrm{T} 3-7$ & VSP8H & Specimen with surface polishing + shot peening $+8 \mathrm{~h}$ surface polishing \\
\hline
\end{tabular}

Table 3 Shot peening test configuration under various conditions

\begin{tabular}{|c|c|c|c|c|c|}
\hline Tests & Specimens & Pressure (psi) & Shot flow rate $(\mathrm{lb} / \mathrm{min})$ & Intensity(A) & Nozzle distance (inch) \\
\hline \multirow[t]{4}{*}{ First batch } & Intrinsic & & & & \\
\hline & SP30, SP30 V & 30 & 10 & $6-8$ & 4 \\
\hline & SP50, SP50 V & 50 & 10 & $6-8$ & 8 \\
\hline & SP70, SP70 V & 70 & 10 & $8-11$ & 15 \\
\hline \multirow[t]{5}{*}{ Second batch } & Intrinsic, VS & & & & \\
\hline & VSP30 & 30 & 10 & $6-8$ & 4 \\
\hline & VSP50 & 50 & 10 & $6-8$ & 8 \\
\hline & VSP60 & 60 & 10 & $6-8$ & 15 \\
\hline & VSP70 & 70 & 10 & $8-11$ & 15 \\
\hline \multirow[t]{3}{*}{ Third batch } & VSP & 30 & 10 & $6-8$ & 4 \\
\hline & VSP2H, VSP4H & 30 & 10 & $6-8$ & 4 \\
\hline & VSP6H, VSP8H & 30 & 10 & $6-8$ & 4 \\
\hline
\end{tabular}

surface morphology and microstructures of specimens under different treatment conditions are also inspected by using optical microscope (Olympus BX60) and scanning electron microscopy (SEM) (JEOL LV SEM 6360LA).

\section{Results and Discussion}

\subsection{Residual Stress Variation}

Figure 3 shows variation of the residual stress under different conditions in the tests. One can observe that the trends of residual stress versus the depth are similar under these conditions. In order to investigate the effect of shot peening intensity on the distribution of the CRS, the residual stress along the variation of depth under different pressures is plotted in Fig. 3a. The CRS attains to a peak value and then decreases to zero away from the surface. It can be seen that the maximum CRS and the depth of CRS generally increase as the shot peening pressure increases. For the same shot peening pressure, residual stress as a function of depth is shown in Fig. $3 b$ for specimens subjected to different post-peening polishing durations, and we 

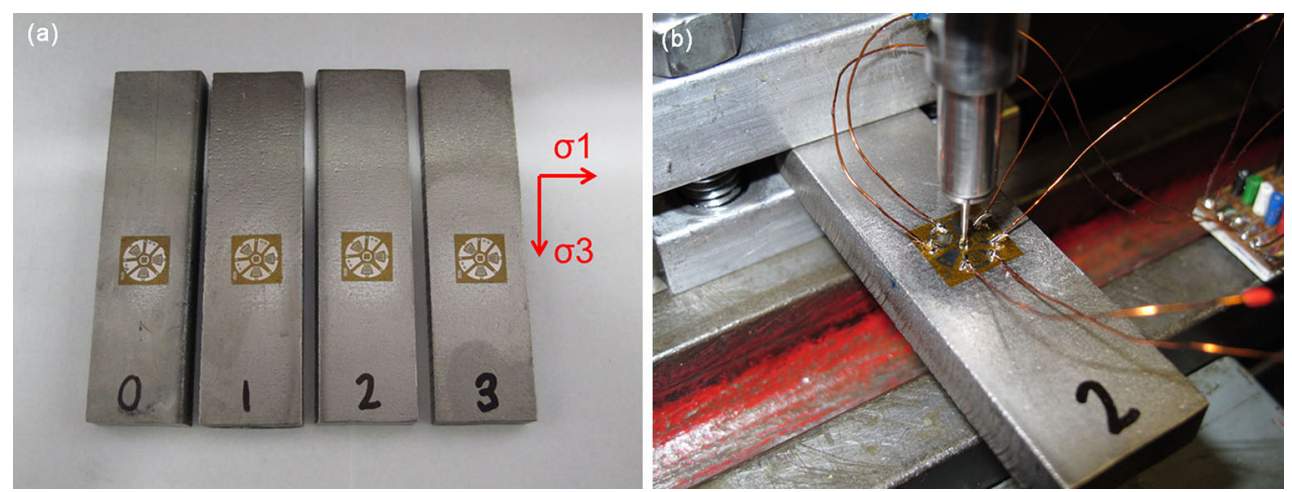

Fig. 2 Residual stress measurement by using orbital hole-drilling method. a Target gauges installed on specimens, b setup for drilling (gauge 2)
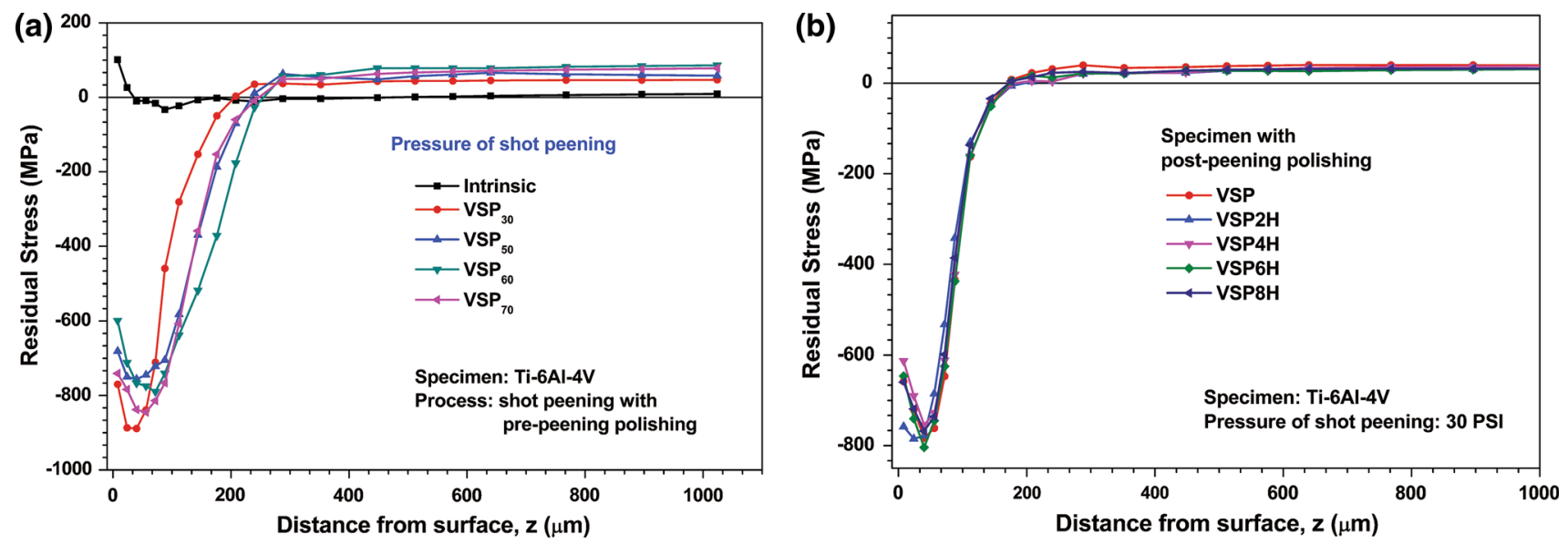

Fig. 3 a Distribution of residual stress along the variation of depths for different shot peening pressures. b Influence of the various polishing times on the distribution of the residual stress of specimen

note that polishing time has little influence on the CRS distribution.

Generally, the fatigue life of shot-peened specimens could be affected by two key characteristics of the CRS layer: the magnitude of the CRS at or near the specimen surface and the depth of the CRS, which is the zero stress crossing where the residual stress state changes from compressive to tensile. We quantify the magnitude and the depth of CRS under various shot peening conditions (shown in Table 4). The surface stress is measured at $16 \mu \mathrm{m}$ from the specimen surface with orbital hole-drilling method. We notice that the small tensile stress at the surface specimens is transformed to compressive stress after shot peening. The depth for the maximum CRS generally increases as the peening intensity increases. For example, in the first batch of tests, the maximum CRS for specimens $\mathrm{SP}_{30}$ and $\mathrm{SP}_{50}$ are located near the surface $(\sim 16 \mu \mathrm{m})$, whereas the specimen $\mathrm{SP}_{70}$ has the maximum CRS at $48 \mu \mathrm{m}$ below the surface of the specimen. The zero crossing depth is around $192 \mu \mathrm{m}$. It is worth to note that the depth of compression zone can be increased by raising shot peening intensity either by increasing the duration of shot impact or the shot velocity [6]. In the second batch of tests, the residual stress profile also displays similar trends. However, the pre-peening polishing treatment produces higher depth of CRS, which are expected to lead to a higher fatigue life. The depth of zero crossing of specimen $\mathrm{VSP}_{60}$ and $\mathrm{VSP}_{70}$ has even reached $264 \mu \mathrm{m}$. It is noted that all specimens in the third batch of tests are subjected to the same shot peening intensity. The depths of the maximum CRS $(40 \mu \mathrm{m})$ and the depth of zero crossing $(192 \mu \mathrm{m})$ are almost the same for all of specimens.

\subsection{Surface Roughness and Fatigue Life}

To illustrate the role of surface finishing in fatigue life, the average surface roughness of specimens under different treatment conditions is shown in Fig. 4. It is noted that the surface roughness under each condition has been collected from six positions, and the $\mathrm{Ra}$ is the average of six data points. One can observe that shot peening produces large surface roughness, but the surface roughness can be 
Table 4 Residual stress and depth of compression zone under various conditions

\begin{tabular}{|c|c|c|c|c|c|}
\hline Tests & Specimens & $\begin{array}{l}\text { Surface stress } \\
(\mathrm{MPa})\end{array}$ & $\begin{array}{l}\text { Max compressive stress } \\
(\mathrm{MPa})\end{array}$ & $\begin{array}{l}\text { Depth of max compressive stress } \\
(\mu \mathrm{m})\end{array}$ & $\begin{array}{l}\text { Depth of zero crossing } \\
(\mu \mathrm{m})\end{array}$ \\
\hline \multirow[t]{4}{*}{ First batch } & Intrinsic & 27 & -22 & 80 & $\sim 320$ \\
\hline & $\begin{array}{l}\text { SP30, } \\
\quad \text { SP30 V }\end{array}$ & -815 & -815 & 16 & 192 \\
\hline & $\begin{array}{l}\text { SP50, } \\
\quad \text { SP50 V }\end{array}$ & -775 & -775 & 16 & 192 \\
\hline & $\begin{array}{l}\text { SP70, } \\
\text { SP70 V }\end{array}$ & -788 & -817 & 48 & 192 \\
\hline \multirow{5}{*}{$\begin{array}{r}\text { Second } \\
\text { batch }\end{array}$} & Intrinsic & 101 & -33 & 88 & 420 \\
\hline & VSP30 & -670 & -749 & 40 & 192 \\
\hline & VSP50 & -681 & -756 & 40 & 224 \\
\hline & VSP60 & -699 & -790 & 56 & 264 \\
\hline & VSP70 & -741 & -845 & 72 & 264 \\
\hline \multirow[t]{7}{*}{ Third batch } & Intrinsic & 101 & -33 & 88 & 480 \\
\hline & VS & -14 & -25 & 24 & 480 \\
\hline & VSP & -658 & -783 & 40 & 192 \\
\hline & VSP2H & -758 & -784 & 40 & 192 \\
\hline & VSP4H & -613 & -754 & 40 & 192 \\
\hline & VSP6H & -646 & -804 & 40 & 191 \\
\hline & VSP8H & -659 & -767 & 40 & 190 \\
\hline
\end{tabular}

reduced by vibration polishing treatment effectively after shot peening. The specimens with shot peening and followed by vibration surface polishing have lower surface roughness. For example, in the first batch of tests, the measured $\mathrm{Ra}$ for the intrinsic and $\mathrm{SP}_{70}$ specimens increases from 0.8 to $5 \mu \mathrm{m}$. After post-peening polishing treatment, the Ra decreases to $3.5 \mu \mathrm{m}$. In the second batch of tests, the $\mathrm{Ra}$ increases from 0.8 to $3.0 \mu \mathrm{m}$ due to increasing shot peening intensity. In the third batch of tests, the Ra in all specimens are relatively low $(<1.5 \mu \mathrm{m})$ due to combination of pre- and post-peening treatments being applied.

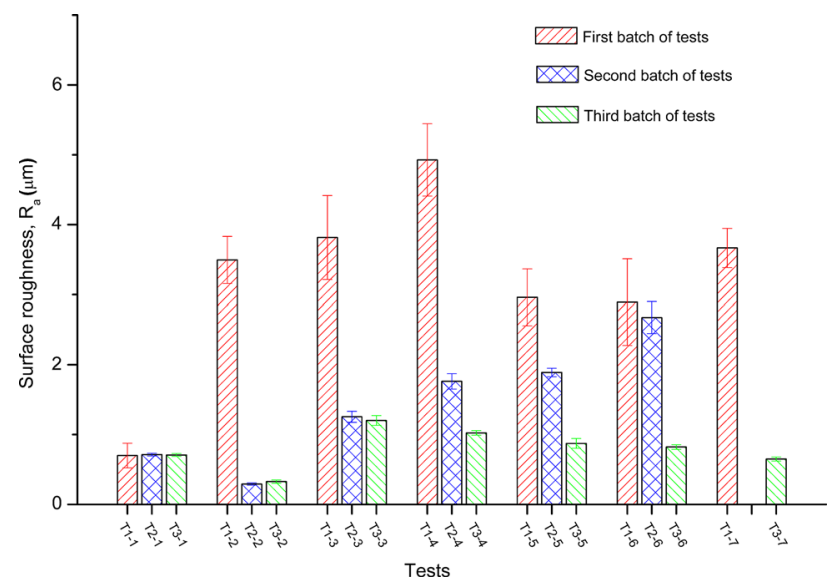

Fig. 4 Surface roughness variation under various treatment conditions in the different tests
Surface roughness data are important for predicting fatigue resistance, as roughness usually results in local stress concentration. Figure 4 indicates that high peening intensity increases the surface roughness of the specimen and probably reduces fatigue performance of the material. Post-peening polishing improves surface quality, but partial removal of the CRS during the polishing process diminishes the benefits of shot peening [26, 27]. This conclusion is consistent with the study of Luong and Hill [9], in which it is concluded that overall fatigue life enhancement from shot peening process is a compromise between positive benefits on the CRS and negative effects of rough surface.

Figure 5 demonstrates variation of the fatigue life of specimens for different conditions. One can observe that specimens with surface polishing treatment show higher fatigue life upon comparing the experimental results from the three batches of tests. In the first batch of tests, data show that shot peening improves fatigue life of the material dramatically when we compare the intrinsic specimen within the shot-peened ones $\mathrm{SP}_{30}, \mathrm{SP}_{50}$ and $\mathrm{SP}_{70}$ (labeled as T1-2, T1-3 and T1-4). The post-peening treatments have further improved the fatigue life of the material and are shown for specimens $\mathrm{SP}_{30} \mathrm{~V}, \mathrm{SP}_{50} \mathrm{~V}$ and $\mathrm{SP}_{70} \mathrm{~V}$ (labeled as T1-5, T1-6 and T1-7). In the second batch of tests, we show that specimens with pre-polishing treatment have higher fatigue life. The maximum fatigue life is for the specimen $\mathrm{VSP}_{60}$ (labeled as T2-5). In the third batch of tests, the 


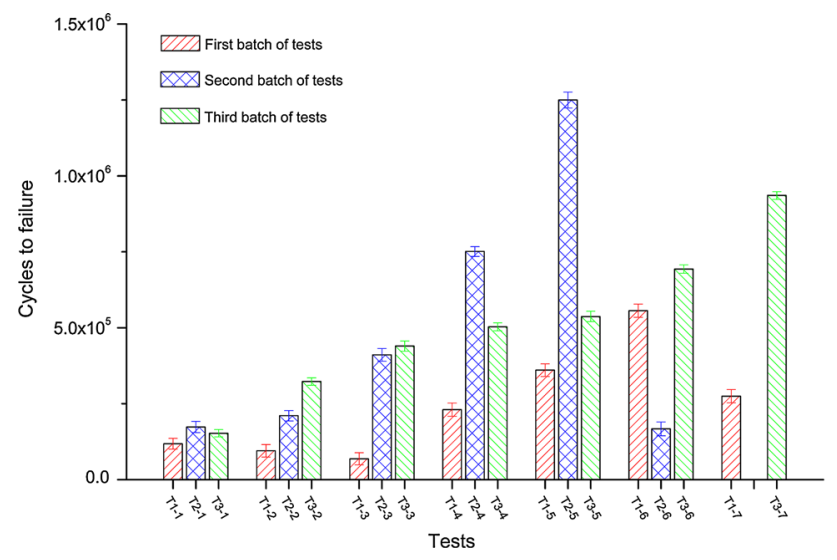

Fig. 5 Fatigue life variation under various treatment conditions in the different tests

combined pre- and post- polishing effects on fatigue performance are analyzed. All of the shot-peened specimens in this batch are subjected to the same peening pressure of 30 psi. Comparing the results between the first and second batch of specimens under same peening pressure, we note that the combined polishing treatment has positive effect on fatigue life enhancement. For example, the maximum fatigue limit for the specimen VSP8H (labeled as T3-7) is about 10 times higher than that of the specimen $\mathrm{SP}_{30}$ (labeled as T1-2), 3 times higher than that of the specimen $\mathrm{SP}_{30} \mathrm{~V}$ (labeled as T1-5) and 1.4 times higher than that of the specimen $\mathrm{V} \mathrm{SP}_{30}$ (labeled as $\mathrm{T} 2-3$ ).

When we investigate the fatigue life of specimen from the standpoint of the role of surface roughness, lower surface roughness generally leads to higher fatigue life. But the correction between the surface roughness decreases and fatigue life enhancement is not monotonic. For example, the specimen $\mathrm{SP}_{50}$ (labeled as T1-3) shows the lowest fatigue life in the first batch of tests (see Fig. 5), even though its surface roughness is not the highest, as shown in Fig. 4. Fatigue performances for shot-peened specimens are influenced by multiple factors. To further clarify the relation between the fatigue enhancement and different surface treatments, the shot peening-induced microstructure is investigated in the next subsection.

\subsection{Microstructure and Surface Morphology}

Figure 6 shows SEM observations of surface morphology for the specimens of $\mathrm{SP}_{30}, \mathrm{SP}_{50}$ and $\mathrm{SP}_{70}$, respectively, in the first batch of tests. We observe that typical crater-like marks of repeated shot impacts are clearly seen on all surfaces. Statistically, the surface of specimen $\mathrm{SP}_{30}$ is significantly smoother than those of specimen $\mathrm{SP}_{50}$ and $\mathrm{SP}_{70}$, from which we can conclude that lower peening intensity leads to smaller surface roughness. It is worth noting that in Fig. 6c evidence of overlapping dimples and deep dent features are seen. These features can result in crack initiation, which implies that this set of shot peening parameters leads to an over-peened condition.

Shot peening specimen surfaces exhibit multiple crack initiation sites. Perhaps, these cracks potentially initiate from surface dents, scratches or notches defects. In the current study, the shot peening-induced microstructure has been examined by fractographic observation. Figures 7 and 8 show the fractographic images of specimens in the first batch of tests. It revealed a mixed microstructure in the cross section of specimen. The intrinsic specimen exhibits grainy feature beneath of the surface. Shot peening treatment produces rough surface, and the deformed layer of specimen exhibits void feature. Meanwhile, as the shot peening intensity increases, the grainy layer goes deeper, the columnar feature also shows in the shot peening-affected area, which will effectively hinders fatigue crack growth. The transformation at the sub-surface of grainy structures in specimen $\mathrm{SP}_{30}$ to columnar structures in specimens $\mathbf{S P}_{50}$ and $\mathrm{SP}_{70}$ is observed in Fig. 7. However, higher shot peening intensity will induce large dents and stress concentration on the
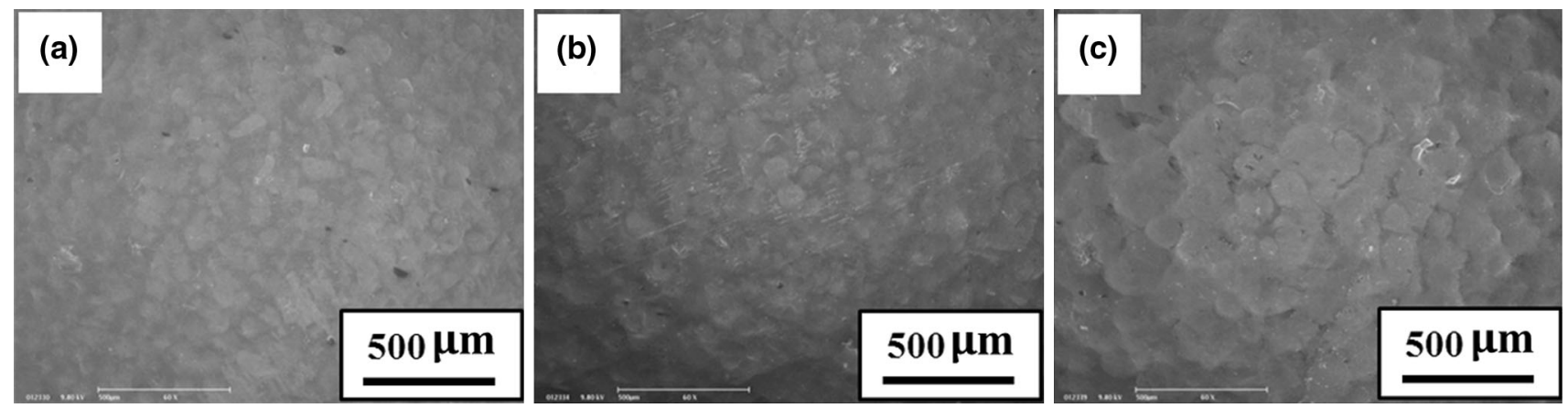

Fig. 6 SEM images of surface morphologies for the specimens under various shot peening pressures in the first batch of tests for: a SP30, b SP50, c SP70 
(a)

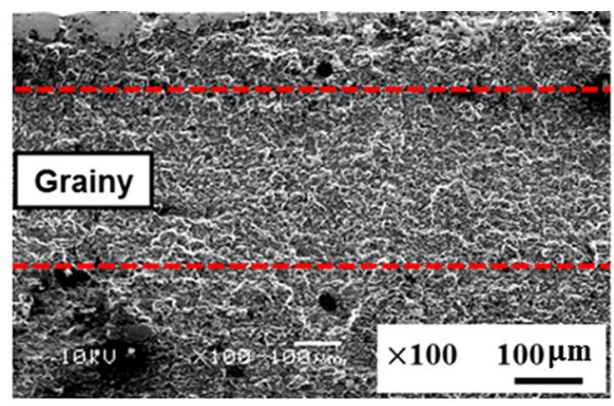

(b)

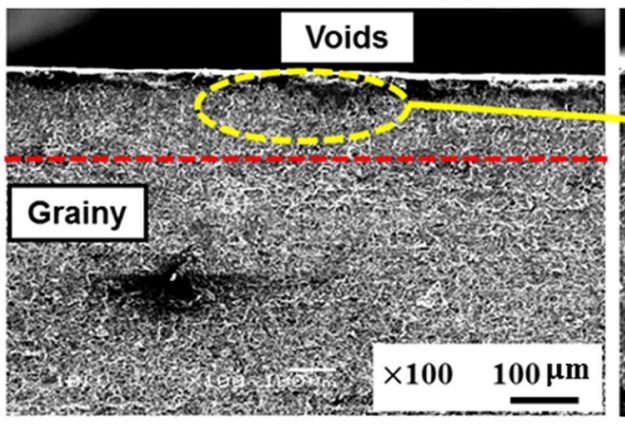

(c)

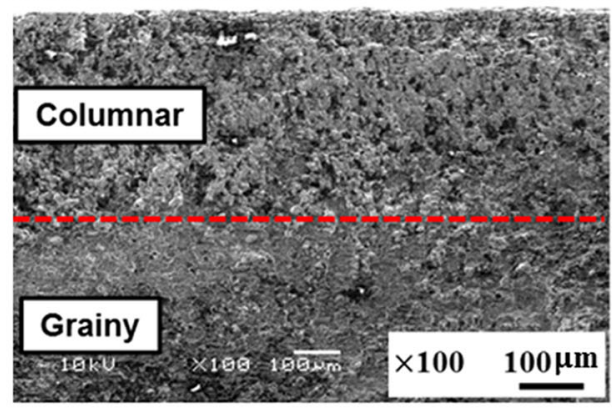

(d)

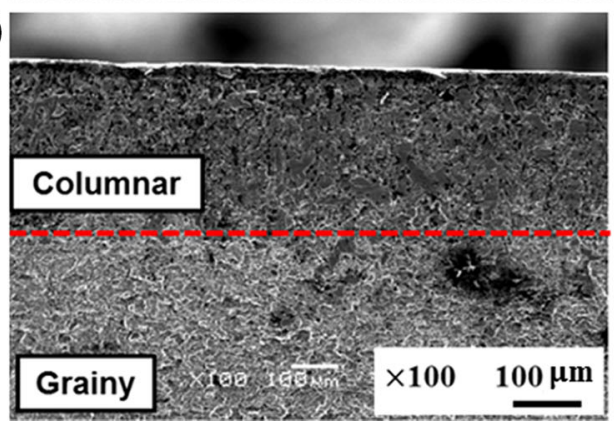

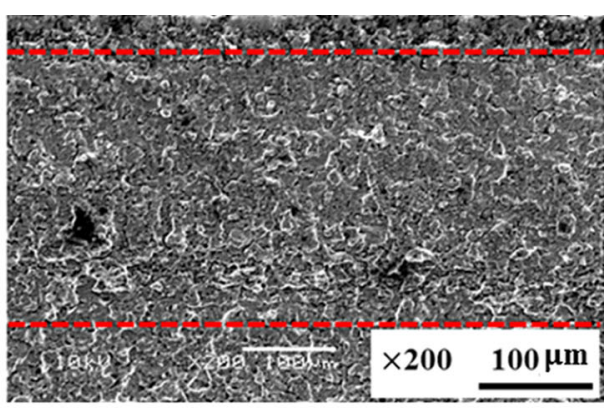
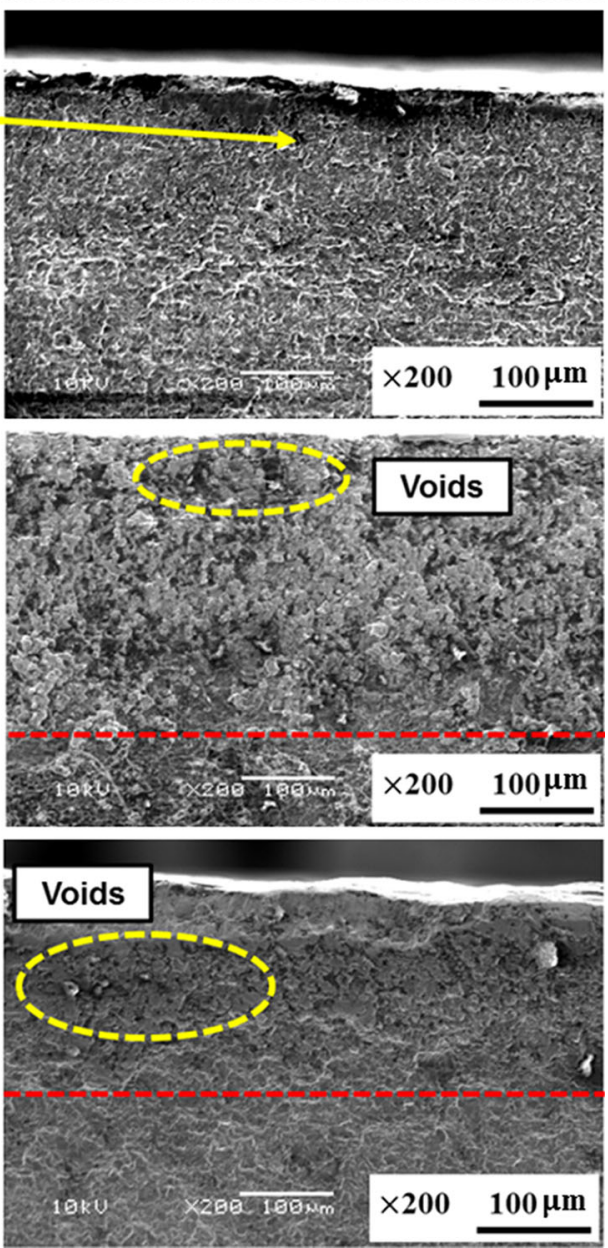

Fig. 7 Fractographic images of specimens in the first batch of tests for: a intrinsic, b SP30, c SP50, d SP70. The red dotted line denotes the border of different layers, while the yellow dotted circle denotes the void located zone

surface, which could be the source of fatigue initiation and then reduce fatigue performance of material. In Fig. 8, it can be seen that the post-peening polishing treatment will remove surface defect significantly. As the results, the fracture initiation source could be reduced. However, this polishing treatment also slightly decreases the thickness of CRS layer, which will reduce the benefits of fatigue life enhancement. From the fatigue test in Fig. 5, the post-peening polishing specimen generally shows higher fatigue life than that of specimen with shot peening only. It implies that the polishing-induced advantages are higher than the CRS layer slightly decrease induced disadvantages in the current study.

It is known that fatigue failure usually is generated from the surface, where the applied loading produces high cyclic stress amplitude [6]. To understand the mechanism of fatigue life enhancement, the surface morphology of specimens has been examined from the second batch of 
(a)
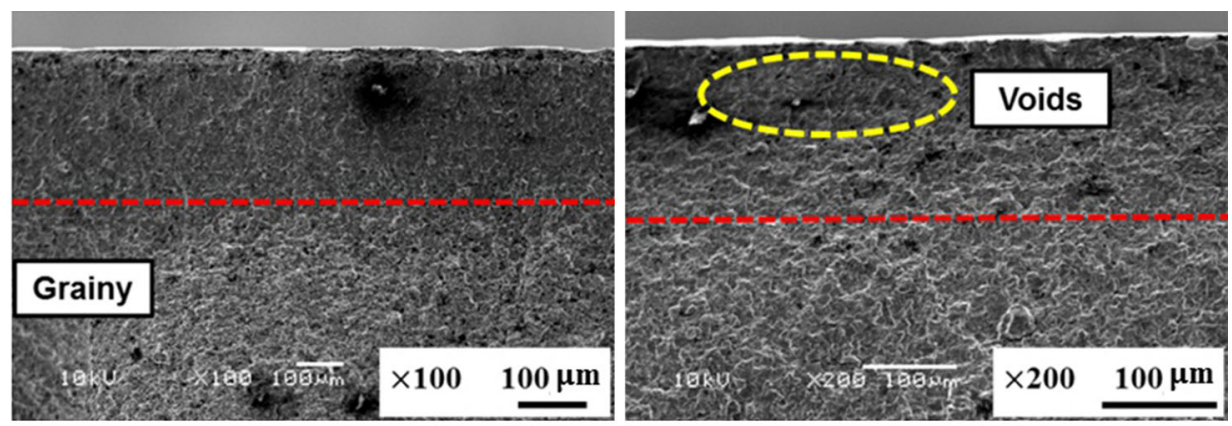

(b)
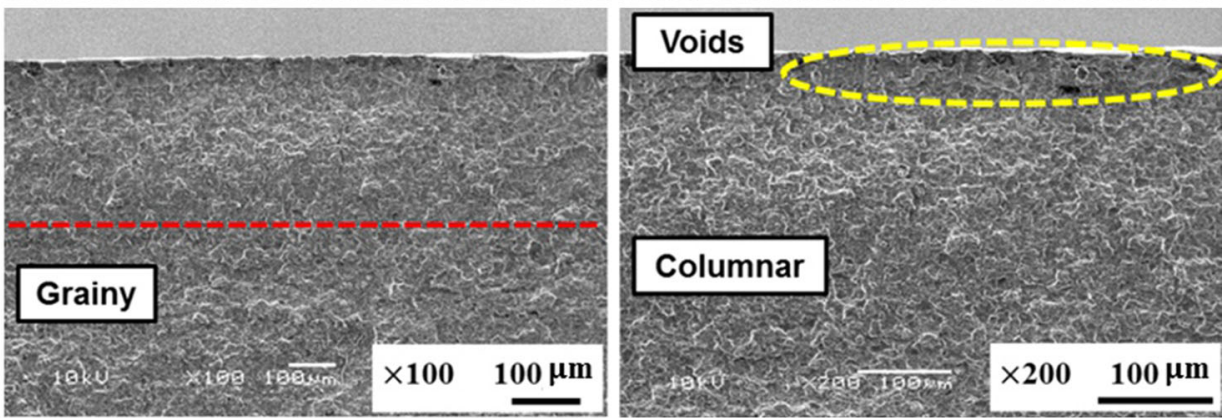

(c)
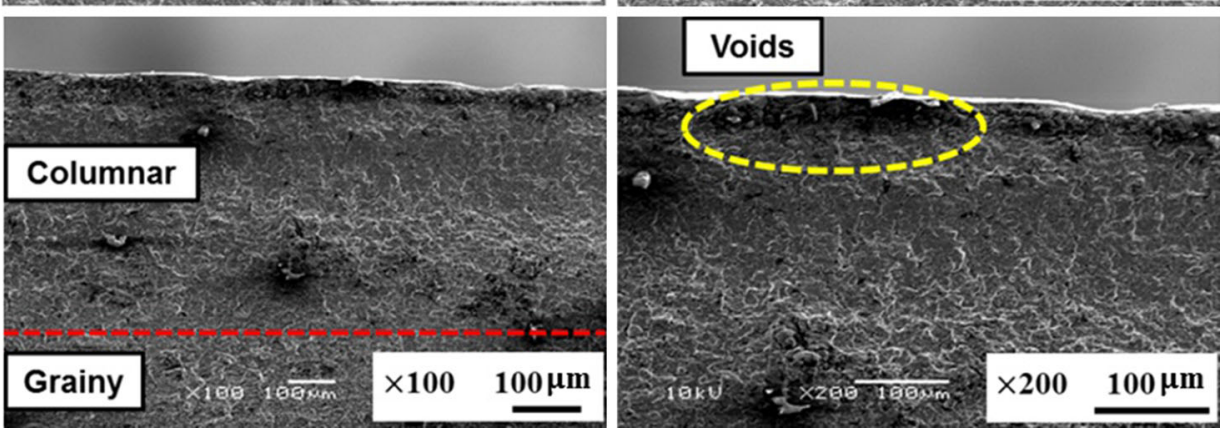

Fig. 8 Fractographic images of specimens under shot peening and post-peening polishing treatments in the first batch of tests for: a SPV30, b SPV50, c SPV70. The red dotted line denotes the border of different layers, while the yellow dotted circle denotes the void located zone

tests. The surface pre-peening polishing treatments are conducted by sand paper grinding. Each specimen is polished until a surface roughness of $\mathrm{Ra} \sim 1.0 \mu \mathrm{m}$. The prepolishing treatment before shot peening can make the specimen surfaces smooth and provide for a more homogeneous surface condition prior to bombardments with metal shots.

Figure 9 displays the surface morphologies of the specimens in second batch of tests. We observe that high-pressure peening produces a rougher surface than low-pressure peening. As the peening intensity increases, the specimen surface shows crater overlapping and pile-up feature. In the second batch of tests, the specimen $\mathrm{VSP}_{70}$ (labeled as T2-6) shows low fatigue life under high cycle loading and this correlated with the highest surface roughness. However, the surface roughness is not the sole critical role for fatigue life under high cycle loading. To inspect the abnormal behavior of specimen $\mathrm{VSP}_{70}$, we track its characteristics based on the CRS, the depth of maximum CRS and the depth of zero crossing. We believe the abnormally low fatigue life for specimen $\mathrm{VSP}_{70}$ was due to the bending during the high-pressure and high-intensity peening condition. Another factor for the occurrence of bending in this specimen is that the thickness of the specimen is relatively thin and can undergo warping when peened from one side.

Figure 10 shows the surface morphology of the specimens in the third batch of tests. Due to the same shot peening intensity, the degree of uneven surfaces decreased gradually with the increase in vibration polishing time after shot peening. To quantify this variation, the surface roughness, $\mathrm{Ra}$, is shown in Fig. 4. The roughness for the shot-peened specimens with post-peening polishing varies in the range of $0.65-1.2 \mu \mathrm{m}$. The specimens with longer post-peening polishing show a smoother surface. 


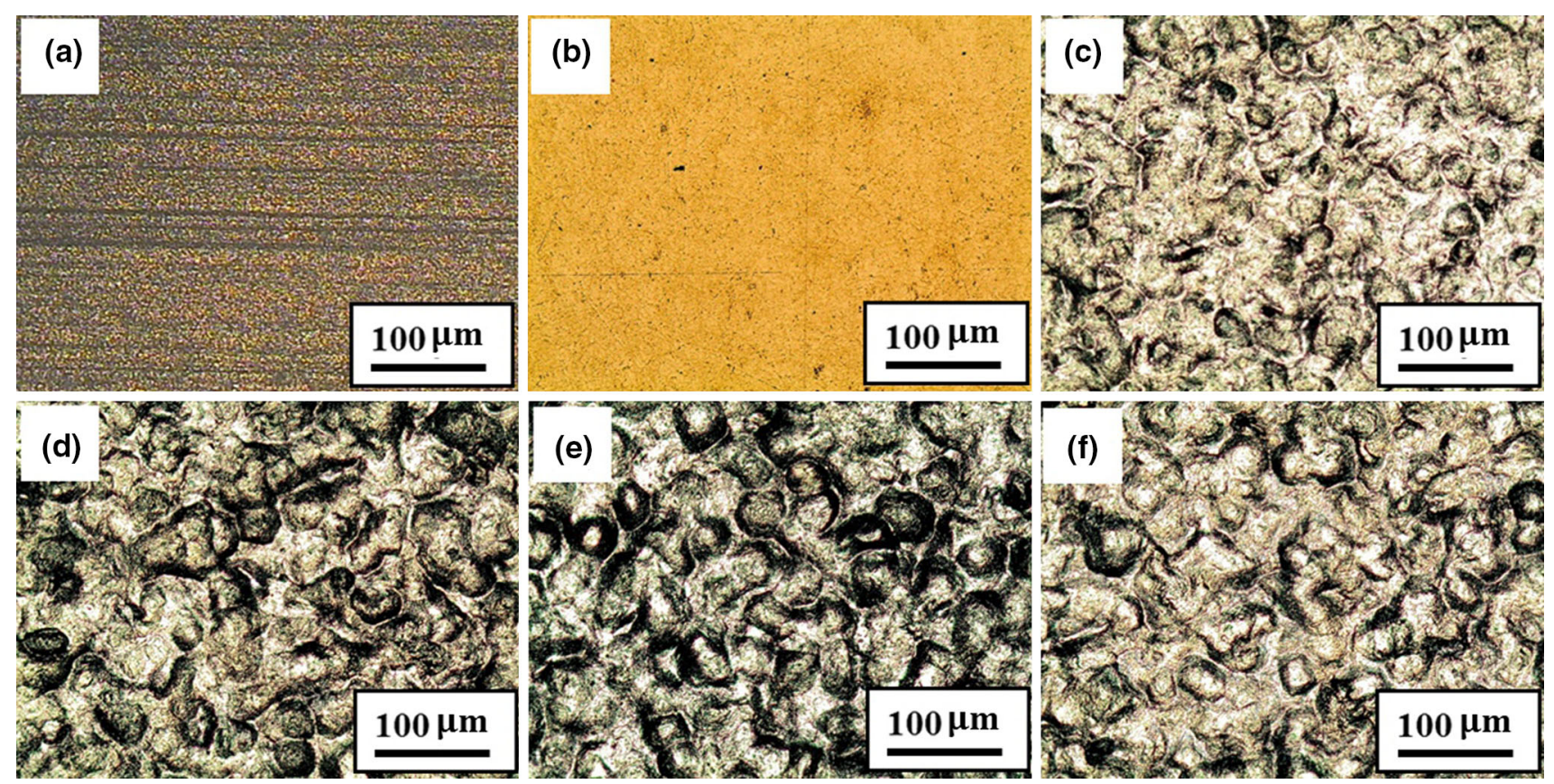

Fig. 9 Surface morphologies of specimens in the second batch of tests for: a intrinsic, b VS, c VSP30, d VSP50, e VSP60, f VSP70
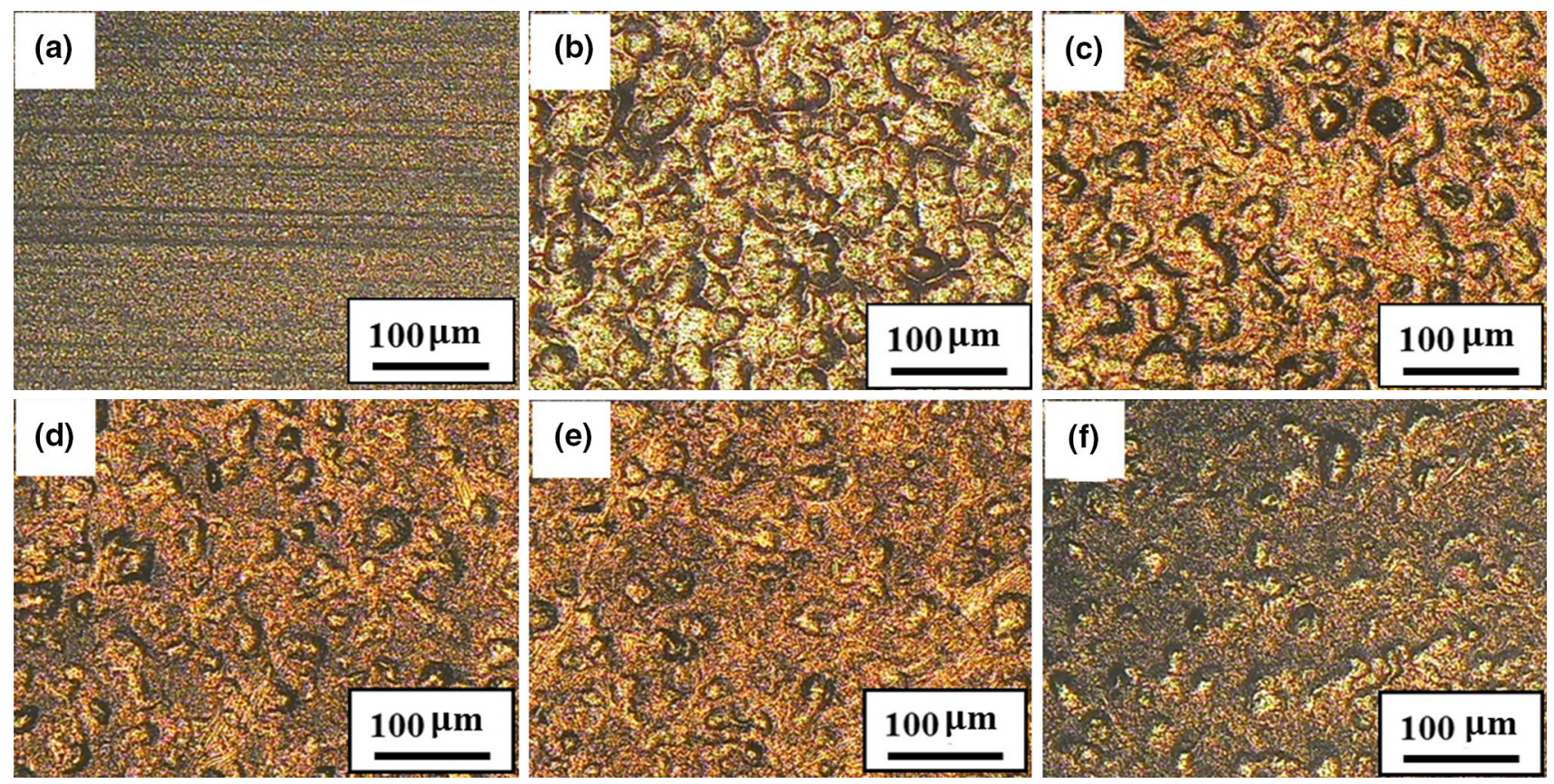

Fig. 10 Surface morphologies of specimens in the third batch of tests for: a intrinsic, b VSP, c VSP2H, d VSP4H, e VSP6H, f VSP8H

\section{Concluding Remarks}

The main findings in this study are summarized as follows:

1. Shot peening produced rough surface on the specimen inducing compressive residual stress. As shot peening intensity increases, the fatigue life generally increases.
2. Shot peening generated a mixed microstructure in the deformed layer of specimen. The transformation at the sub-surface to a columnar structure can be observed as the peening pressure increases.

3. Pre-peening polishing treatment removes the defects at the specimen surface, and thus, the fatigue life can be consequently enhanced. 
4. Post-peening polishing treatment improves surface quality of specimen after shot peening. This effectively reduces likelihood of fatigue crack initiation, even though this treatment slightly reduces the thickness of the CRS layer. We find that the post-peening polishing-induced benefit outweighs the disadvantage of a slight reduction in the CRS layer thickness.

5. Under same shot peening pressure, the specimens with combined pre- and post-peening polishing treatment show higher fatigue life.

Acknowledgement The financial support for this work from the Aerospace Program and Agency for Science, Technology and Research, Singapore (A*STAR), is gratefully acknowledged.

\section{References}

[1] P. O'Hara, Mater. Des. 5, 161 (1984)

[2] Q. Feng, C.H. Jiang, Z. Xu, L.C. Xie, V. Ji, Surf. Coat. Technol. 226, 140 (2013)

[3] H.Y. Miao, S. Larose, C. Perron, M. Lvesque, Adv. Eng. Softw. 42, 963 (2011)

[4] M.N. James, D.J. Hughes, Z. Chen, H. Lombard, D.G. Hattingh, D. Asquith, J.R. Yates, P.J. Webster, Eng. Fail. Anal. 14, 384 (2007)

[5] Z.M. Song, L.M. Lei, B. Zhang, X. Huang, G.P. Zhang, J. Mater. Sci. Technol. 28, 614 (2012)

[6] J. Liu, M. Pang, Int. J. Fatigue 43, 134 (2012)

[7] N. Habibi, S.M. H-Gangaraj, G.H. Farrahi, G.H. Majzoobi, A.H. Mahmoudi, M. Daghigh, A. Yari, A. Moridi, Mater. Des. 36, $250(2012)$

[8] X. Feng, J.K. Qiu, Y.J. Ma, J.F. Lei, Y.Y. Cui, X.H. Wu, R. Yang, J. Mater. Sci. Technol. 32, 362 (2016)

[9] H. Luong, M.R. Hill, Mater. Sci. Eng. A 527, 699 (2010)

[10] A. Zammit, M. Mhaede, M. Grech, S. Abela, L. Wagner, Mater. Sci. Eng. A 545, 78 (2012)

[11] K.T. Cho, K. Song, S.H. Oh, Y.K. Lee, K.M. Lim, W.B. Lee, Mater. Sci. Eng. A 543, 44 (2012)
[12] G. Fargas, J.J. Roa, A. Mateo, Mater. Sci. Eng. A 641, 290 (2015)

[13] S. Kikuchi, Y. Nakamura, K. Nambu, M. Ando, Mater. Sci. Eng. A 652, 279 (2016)

[14] S. Wang, Y. Li, M. Yao, R. Wang, J. Mater. Process. Technol. 73, 57 (1998)

[15] P. Fu, C.H. Jiang, Mater. Des. 56, 1034 (2014)

[16] L. Trsko, O. Bokuvka, F. Novy, M. Guagliano, Mater. Des. 57, 103 (2014)

[17] A. Moridi, S.M. Hassani-Gangaraj, S. Vezz, L. Trko, M. Guagliano, Surf. Coat. Technol. 283, 247 (2015)

[18] B.L. Boyce, X. Chen, J.O. Peters, J.W. Hutchinson, R.O. Ritchie, Mater. Sci. Eng. A 349, 48 (2003)

[19] A.S. Franchim, V.S. de Campos, D.N. Travessa, C.deM. Neto, Mater. Des. 30, 1556 (2009)

[20] L. Xie, C. Jiang, W. Lu, K. Zhan, Y. Chen, Mater. Sci. Eng. A 528, 3423 (2011)

[21] X.P. Jiang, C.S. Man, M.J. Shepard, T. Zhai, Mater. Sci. Eng. A 468-470, 137 (2007)

[22] X.C. Zhang, Y.K. Zhang, J.Z. Lu, F.Z. Xuan, Z.D. Wang, S.T. Tu, Mater. Sci. Eng. A 527, 3411 (2010)

[23] Y.K. Gao, Mater. Sci. Eng. A 528, 3823 (2011)

[24] S.A. Martinez, S. Sathish, M.P. Blodgett, S. Mall, S. Namjoshi, Mater. Sci. Eng. A 399, 58 (2005)

[25] H. Lee, S. Mall, Mater. Sci. Eng. A 366, 412 (2004)

[26] P. Peyre, X. Scherpereel, L. Berthe, C. Carboni, R. Fabbro, G. Beranger, C. Lemaitre, Mater. Sci. Eng. A 280, 294 (2000)

[27] C.S. Montross, T. Wei, L. Ye, G. Clark, Y.W. Mai, Int. J. Fatigue 24, 1021 (2002)

[28] J. Champaigne, Controlled Shot Peening (Electronics Inc., 1989)

[29] G.S. Schajer, Trans. ASME J. Eng. Mater. Technol. 110, 338 (1988)

[30] G.S. Schajer, Trans. ASME J. Eng. Mater. Technol. 110, 344 (1988)

[31] P.V. Grant, J.D. Lord, P.S. Whitehead, The Measurement of Residual Stresses by the Incremental Hole Drilling Technique. Measurement Good Practice Guide No. 53 (British National Physical Laboratory, 2006)

[32] J.H. Zuo, Z.G. Wang, E.H. Han, Mater. Sci. Eng. A 473, 147 (2008) 